\title{
Policy Interventions Shaping HIV Prevention: Providers' Active Role in the HIV Continuum of Care
}

Health Education \& Behavior

2018, Vol. 45(5) 714-722

(C) 2018 Society for Public

Health Education

Article reuse guidelines:

sagepub.com/journals-permissions

DOI: |0.1|77//090|98||876068|

journals.sagepub.com/home/heb

(\$SAGE

\author{
Rogério M. Pinto, PhD', Susan S. Witte, PhD', \\ Prema L. Filippone, $\mathrm{MSW}^{2}$, C. Jean Choi, $\mathrm{MS}^{3}$, \\ and Melanie Wall, $\mathbf{P h D}^{2}$
}

\begin{abstract}
The U.S. Centers for Disease Control and Prevention (CDC) Diffusion of Effective Behavioral Interventions project has disseminated HIV behavioral interventions (EBIs) across the United States since the 1990s. In 20II, the CDC launched the High-Impact HIV Prevention (HIP) project, providing EBIs plus high-impact services (HIV testing, primary care, and support services). Providers (nurses, social workers, educators) are unable to consistently make linkages; thus, numerous at-risk individuals are not benefitting from HIP. Research on providers' roles in the HIV Continuum of Care-linking clients to HIV testing, primary care, and support services-is lacking. This article helps fill this gap with evidence that providers exposed to EBls, whose agencies offer EBls, more frequently link clients to high-impact services. This is based on diffusion of innovations theory, where individuals in social networks influence one another's adoption of innovations. We hypothesize that providers are exposed to EBls via training, reading and hearing about EBls, and/or discussing EBls with colleagues. We used crosssectional data from 379 providers from 36 agencies in New York City. We used multilevel ordinal logistic regression models to test associations between provider exposure to EBls (agency provides EBls) and frequency of linkages to high-impact services. Providers exposed to greater numbers of EBls more frequently link clients to HIV, hepatitis C (HEP-C), and sexually transmitted infections testing; to primary care; and to drug treatment and mental health services. Providers link clients most frequently to primary care and HIV testing and least frequently to HEP-C testing and syringe exchange. Findings suggest a dose effect, with exposure to more EBls resulting in more linkages. Findings show a staged, evidence-based prevention approach that includes exposure to EBls, leading to providers linking clients to high-impact services. There needs to be emphasis on inspiring providers to engage with high-impact services at the elevated levels needed to end the epidemic.
\end{abstract}

\section{Keywords}

dissemination and implementation, high-impact HIV services, HIV continuum of care, linkages to care, services providers

The U.S. Centers for Disease Control and Prevention (CDC) reports that at the end of 2014, nearly one million persons lived with human immunodeficiency virus (HIV) infection in the United States; nearly 44,000 new cases are reported annually. With widespread antiretroviral therapy (ART), the number of people living with HIV is rising and rates of new infections are stable (CDC, 2016). The effectiveness of ART as HIV prevention rests on timely access to testing and ART initiation (first steps of the HIV Continuum of Care, "care continuum"), and access to support services (CDC, 2015b; Panel on Antiretroviral Guidelines for Adults and Adolescents, 2016). ART lowers the viral load in the blood stream, making transmission less likely (Cohen, McCauley, \& Gamble, 2012; Dodd, Garnett, \& Hallett, 2010; Porco et al., 2004; Thompson et al., 2012). Therefore, HIV testing, linkage to care and ART reduce HIV infections (Cohen et al., 2011). Treatment of sexually transmitted infections (STIs; Baeten et al., 2008; Fleming \& Wasserheit, 1999; Zuckerman et al., 2007), of mental disorders and drug addiction are recommended to further reduce risks for transmission (Fuller, Ford, \& Rudolph, 2009).

Since 1999, the CDC has disseminated 34 evidence-based behavioral interventions (EBIs) through the Diffusion of

\footnotetext{
'University of Michigan-Ann Arbor, Ann Arbor, MI, USA

${ }^{2}$ Columbia University, New York, NY, USA

${ }^{3}$ New York State Psychiatric Institute, New York, NY, USA
}

\section{Corresponding Author:}

Rogério M. Pinto, School of Social Work, University of Michigan-Ann Arbor, 1080 South University Avenue, Ann Arbor, MI 48109, USA.

Email: ropinto@umich.edu 
Effective Behavioral Interventions (DEBI) project to reduce HIV morbidity, mortality, and health disparities (CDC, 2015a). In 2011, DEBI morphed into CDC High-Impact HIV Prevention (HIP) project, to provide high-impact intervention to high-risk individuals, including EBIs, HIV testing, primary care, and support services to help clients adhere to ART (Centers for Disease Control and Prevention, National Center for HIV/AIDS, Viral Hepatitis, STD, and TB Prevention Division of HIV/AIDS Prevention, 2011). Individuals at risk for HIV infection access the care continuum assisted by service providers ("providers"), counselors, case managers, navigators, outreach workers, and supervisors whose responsibilities include linkages to HIV services. Regrettably, at-risk individuals are not consistently linked to or retained in care (Del Rio \& Mayer, 2013; Pinto, Witte, Filippone, Whitman, \& Baird, 2017). Little research has been conducted to examine this matter, due to the fast shift in HIV policy interventions (Mugavero, Norton, \& Saag, 2011; Zaller, Fu, Nunn, \& Beckwith, 2011). This article helps close this gap by (1) showing how a shift in HIV prevention policy has shaped current practice, (2) identifying a staged approach to HIV prevention, and (3) informing future research regarding linkage-making practices.

\section{High-Impact HIV Prevention Project}

Starting in 2002, the CDC launched DEBI to disseminate EBIs across the US. In response to changes in the epidemiology of HIV transmission, in 2011, the CDC launched the High-Impact HIV/AIDS Prevention project (CDC, 2015a). HIP includes a compendium of 9 best practices for promoting linkage and retention in care, and 84 HIV risk-reduction EBIs, 34 of which are behavioral interventions formerly known as "DEBIs." In 2015, the CDC awarded a total of \$216 million to U.S. agencies to deliver HIV-prevention programs (National Center for HIV/AIDS, Viral Hepatitis, STD, and TB Prevention Division of HIV/AIDS Prevention, 2015). Roughly between 1999 and 2011, these agencies focused on EBIs; with HIP, agencies now promote linkages and retention in care while still providing EBIs. HIP reflects the Joint United Nations Programme on HIV/AIDS's target to end the AIDS epidemic: by $2020,90 \%$ of people living with HIV will be aware of their status; $90 \%$ with HIV infection will receive ART; and 90\% receiving ART will achieve viral suppression (UNAIDS, 2014).

In the HIP project, HIV prevention is guided by key considerations encouraging providers to offer or refer their clients to high-impact services. The CDC prioritizes integration of services targeting at-risk populations, and which are costeffective and feasibly delivered. Providers link to and retain clients in care and reengage those who drop out of care (Gardner et al., 2012; Rapp, et al., 2013). Less is known about loss to follow-up, but we know that adolescents who experience shorter intervals between testing and care are more likely to engage in long-term care, compared to those who experience longer intervals (Carey et al., 2015).
Integrated linkages improve outcomes by reducing client visits and by increasing access to care (Kaaya et al., 2013).

\section{Conceptual Framework}

\section{Policy Intervention Framework}

Our understanding of how providers are responding to the HIP project is drawn from a policy intervention framework developed by the CDC-funded Center of Excellence for Training and Research Translation to evaluate policies and practices (Center for Training and Research Translation, 2012). The framework is based on logic models that evolve as health promotion and prevention projects also evolve overtime, in this case from DEBI to HIP (including ongoing HIP practices). This approach reflects the continual interplay across two or more policy interventions, the practices that stem from them, and the path that might lead to successful outcomes. Researchers and providers can revise the framework to progressively capture nuances of policy shifts.

Figure 1 provides a modified model depicting the temporal connection between Policy Intervention I (DEBI) and Policy Intervention II (HIP), a staged approach to prevention, as follows: DEBI mandate (1999-2011) characterized by EBIs followed by HIP (2011-present) including all high impact services. The mechanism hypothesized to influence provider linkage behaviors comprises their exposure to EBIs (explained below). In this article, we focused on and thus measured one key behavior, the rate at which providers make linkages to high impact services.

\section{Exposure to EBls at the Local Level}

"Environmental exposure" is derived from Rogers' diffusion of innovations theory (Rogers, 1995), where individuals in social networks influence one another's adoption of innovations. The theory emphasizes the way networks enable innovative practices to spread over time, as follows. A small number of providers in each agency (as few as one or two) are trained to deliver the EBIs offered by their agencies. Because DEBI ran for more than two decades, providers who were not trained were nonetheless exposed to EBIs (Dolcini et al., 2010). They actively conducted outreach to vulnerable populations, adopted new strategies for matching services to client's needs, and linked clients to EBIs. Discussions about the advantages and limitations of EBIs are common in agencies that offer them; therefore, providers are exposed by reading announcements and by hearing about EBIs. Given the proximity of providers within agencies, communications about linkages are recurrent. As the CDC began to de-emphasize some EBIs and emphasize the integration of all high-impact interventions, providers began to draw on the skills they had developed under DEBI to fulfill HIP mandates. We hypothesize that exposure to EBIs improves the likelihood of linkagemaking to HIV, hepatitis C (HEP-C), and STI testing; primary care; drug and mental health treatment; and syringe exchange. 


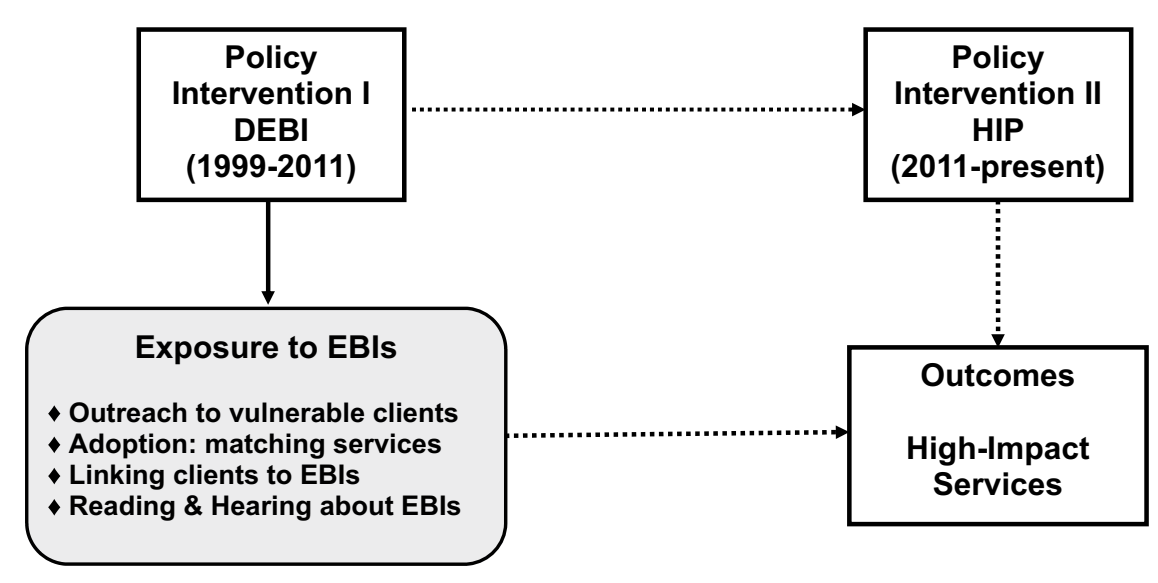

Figure I. Provider exposure to evidence-based behavioral interventions (EBIs) influences high-impact services.

\section{Method}

For the current study, we used baseline data from an NIMHfunded (R01MH095676) longitudinal project, Implementation Collaboration for Implementation ("Project ICI"). Project ICI examines providers' implementation of HIV services in primary care, outpatient treatment, and prevention programs in New York City (NYC). Project ICI collected survey data on 379 providers in 36 service agencies in 2013-2014. Following community-engaged research practices, we partnered with stakeholders to establish study aims, develop and pilot survey questions, and collect and analyze data (Pinto, Spector, Rahman, \& Gastolomendo, 2015; Pinto, Spector, \& Valera, 2011). The study was approved by the Institutional Review Boards at Columbia University and at the University of Michigan.

\section{Procedures}

Agency Recruitment. We used a convenience sample of 36 agencies funded by the NYC Department of Health and/or the CDC to provide HIV-related services, with the goal of enrolling 360 providers. We recruited from a list of more than 100 agencies. We contacted all agencies via e-mail, and we followed up by phone. Study staff contacted agency representatives by phone, outlining procedures and inclusion criteria and developing a data collection plan. We enrolled the first 36 agencies that accepted our terms. Nine agencies were in Manhattan, eight in Brooklyn, four in Queens, three in the Bronx, and nine had sites in two or more boroughs. Each agency received a computer (valued at \$1,000) as an incentive to participate.

Provider Recruitment. To be included, a provider had to offer and/or make linkages to HIV services. There were no exclusion criteria. The average number of providers per agency was 10 (2 to 25 ), representing from $10 \%$ (large agencies) to $100 \%$ (small agencies) of eligible providers. Providers received $\$ 20$ gift cards after interviews.
Data Collection. Project staff implemented computer-assisted face-to-face interviews. We used notebook computers loaded with password-protected survey software powered by DATSTAT Illume 6.0. Provider interviews lasted 45 to $60 \mathrm{~min}-$ utes. Agency leaders took a short Organizational Survey (15-20 minutes). Participants read and signed informed consent prior to interviews.

Surveys. The Organizational Survey included 45 questions: (1) organizational capacity, (2) staff preparedness, (3) organization's prior research experience, (4) organization's delivery EBIs, and (5) organization's linkage to services. The Provider Survey comprised 150 questions about (1) provider's job description and demographic information, (2) opinions of and experiences with interagency collaboration, (3) research experience, (4) attitudes about and experience making linkages to high-impact services, and (5) job satisfaction. Surveys were piloted with six providers whose responses were used to help refine questions and ensure validity. Prior to baseline collection, the survey was repiloted with six new volunteers.

\section{Measures}

Outcome: "Type and Frequency of Linkage to Each High-Impact Service." Participants were asked, "How often have you referred clients in the past 6 months to HIV, HEP-C, and STI testing, and primary care, drug treatment, mental health or syringe exchange." Categorical responses included the following: "no referrals," "once a month," "once a week," and "several times a week." The term "linkage" is used to describe attempts at "linking" clients to services (e.g., HIV testing) by, for example, phoning, e-mailing, or walking the client to meet another provider who can provide that service. We use "linkage" here based on our experiences as practitioners and on the expertise of our research partners who make linkages in their day-to-day work or supervise those who do. 
Primary Predictor: "Degree of Exposure to EB/s." Participants were given a list of EBIs currently funded by the CDC and asked, "Please indicate whether or not your agency has had each of these EBIs" ("yes," "no," "I don't know"). Participants who marked "yes" to any EBI were considered "environmentally exposed." Those who responded "no" or "I don't know" were considered "not exposed." Degree of exposure was measured by these categories: participant marked no or $I$ don't know $=0$ EBIs; participant marked 1, 2, 3, or $\geq 4$ EBIs.

Controls. Age was measured in years. Ethnicity included Latino/Hispanic or non-Latino/Hispanic. Race included White, Black/African American, "more than one race," and a grouping of Asian, Native Hawaiian, Alaskan Native, and American Indian. Gender was categorized as male or female. Education included high school, associate's degree, bachelor's degree(s), master's degree(s), and $\mathrm{PhD}(\mathrm{s})$. Work positions included supervisor, counselor, case manager, navigator, educator/outreach, and program administrator. In order to control for providers linking clients to services provided in their own agencies, an agency level indicator was obtained from administrators of types of in-house services provided. To control for different caseloads, we used participant responses to "Please tell us, on average, how many clients you provide services to each week (individually or in groups)?" with response options, "Fewer than 30 clients," "31 to 50 clients," and "More than 50 clients."

\section{Data Analysis}

We calculated descriptive proportions and means (standard deviations) of agency and provider characteristics. For each high-impact service for which frequency of linkages was measured, a multilevel ordinal logistic regression model (using SAS GLIMMIX) was used to test the association between degree of exposure and the frequency of linkages to each service. We controlled for age, gender, race, education, work position, caseload, and in-house service (for the type of linkage being examined in the outcome). Clustering of providers within agencies was controlled in the multilevel ordinal logistic model through the inclusion of a random intercept at the agency level. We chose to use an ordinal logistic link function to reflect the four ordered category outcomes measuring increasing frequencies of linkages, and the proportional odds assumption was verified for each type of service. Estimated odds ratios and 95\% confidence intervals from the multilevel ordinal logistic model are presented for all predictors. Odds ratios greater (lower) than 1 indicate that the predictor is associated with higher (lower) frequency of linkages. Given our primary interest in the effect of exposure to EBIs and the observation that 85 providers reported that they did not know if their agencies offered EBIs, we performed additional sensitivity analyses to check robustness of our findings. Specifically, we reran all multilevel ordinal logistic regression models on a smaller sample $(N=294)$, dropping
Table I. Sample Demographic Characteristics $(N=379)$.

\begin{tabular}{|c|c|c|}
\hline Characteristic & $n$ & $\%$ \\
\hline \multicolumn{3}{|l|}{ Age, years $(M=4 I, S D=12)$} \\
\hline \multicolumn{3}{|l|}{ Gender } \\
\hline Male & 143 & 38 \\
\hline Female & 236 & 62 \\
\hline \multicolumn{3}{|l|}{ Ethnicity } \\
\hline Hispanic or Latino & 241 & 64 \\
\hline Not Hispanic or Latino & 138 & 36 \\
\hline \multicolumn{3}{|l|}{ Race } \\
\hline More than one race & 64 & 17 \\
\hline White & 102 & 27 \\
\hline Black or African American & 193 & 51 \\
\hline $\begin{array}{l}\text { Native Hawaiian, Asian, American } \\
\text { Indian, Alaskan Native }\end{array}$ & 20 & 5 \\
\hline \multicolumn{3}{|l|}{ Highest level of education } \\
\hline Less than high school & 6 & 2 \\
\hline High school diploma/GED & 87 & 23 \\
\hline Associate's degree & 46 & 12 \\
\hline Bachelor's degree & 122 & 32 \\
\hline Master's degree & 115 & 30 \\
\hline Doctoral degree & 3 & I \\
\hline \multicolumn{3}{|l|}{ Work position } \\
\hline Supervisor & 56 & 15 \\
\hline Counselor & 77 & 20 \\
\hline Case manager & 100 & 26 \\
\hline Navigator & 27 & 7 \\
\hline Educator/outreach & 57 & 15 \\
\hline Program administrator & 55 & 15 \\
\hline Other & 7 & 2 \\
\hline
\end{tabular}

those who reported "I don't know." The model results (available on request) are very similar to the original analyses.

\section{Results}

\section{Agency and Provider Samples}

All agencies were nonprofit organizations providing medical services (e.g., HIV testing and care) and/or psychosocial services (e.g., HIV counseling, workshops, homeless shelter). Twenty-four agencies had budgets below \$10 million. Eight employed more than 100 providers. The number of in-house services was $3.8(S D=2.1$; range $0-7)$. The most common in-house service was HIV testing ( $81 \%$ of agencies) and the least common syringe exchange (25\% of agencies).

The sample comprised 379 providers (Table 1). Sixty-two percent were women. A total of 241 providers (64\%) identified as Hispanic/Latino. Racially, they identified as follows: 193 (51\%) Black/African American; 102 (27\%) White; 64 (17\%) "more than one race"; and 20 (5\%) Hawaiian Native, Asian, American Indian, or Alaskan Native. The mean age was 41 years $(S D=12)$. Providers identified their job roles as follows: $100(26 \%)$ case managers, $77(20 \%)$ counselors, 57 


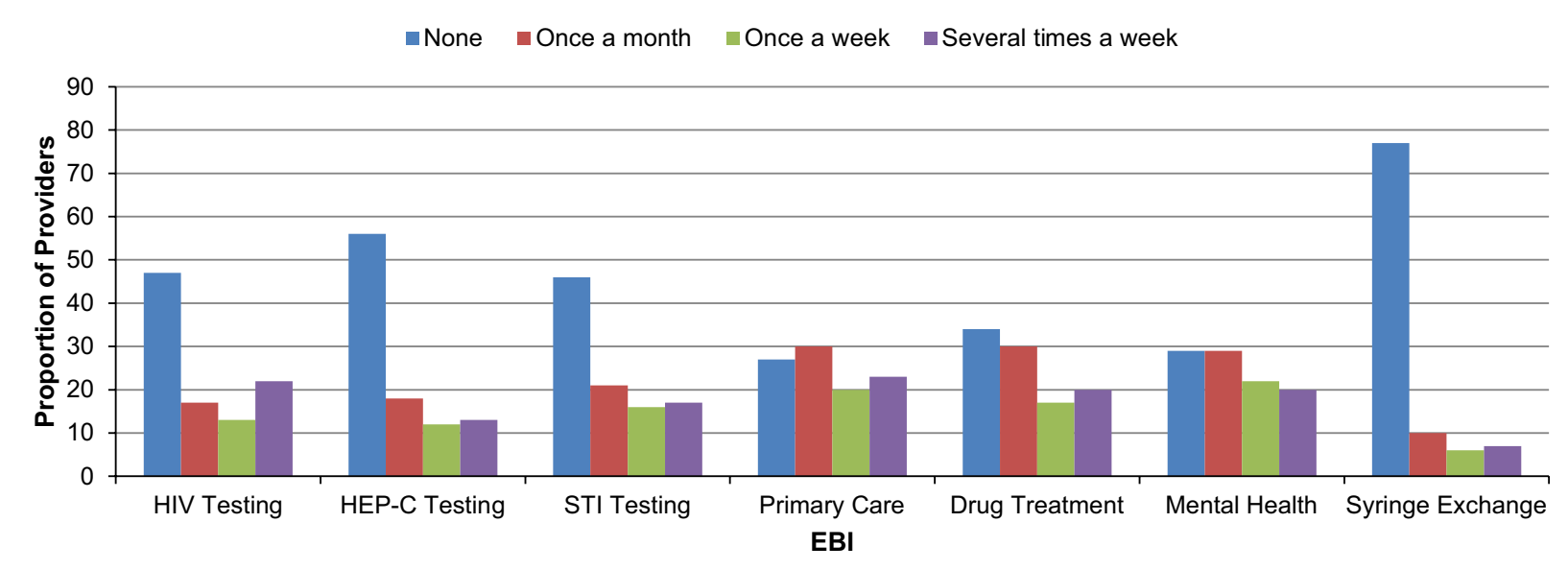

Figure 2. Frequency of linkages made in the past 6 months.

(15\%) education/outreach, 56 (15\%) supervisors (e.g., of counselors, case managers, etc.), 55 (15\%) program administrators, $27(7 \%)$ health navigators, and $7(2 \%)$ "Other." The largest proportion (122, or 32\%) had bachelor's degrees, followed by 115 (30\%) with master's degrees. Most providers $(209,55 \%)$ served fewer than 30 clients per week.

\section{Environmental Exposure}

Of 379 providers, $237(63 \%)$ were exposed to at least one EBI; there were 102 (27\%) providers exposed to four or more. Thirty-seven percent (142) were not exposed (this figure includes 85 providers who checked "I don't know").

\section{Frequency of Linkages}

Figure 2 shows frequencies of linkages to high-impact services. Most frequent ("several times a week") linkages were to primary care and HIV testing. Least frequent linkages (no linkages in past 6 months) were to HEP-C testing and syringe exchange services.

\section{Predictors of Frequency of Linkages}

Table 2 shows that exposure to EBIs was associated with providers more frequently linking clients to HIV, HEP-C and STI testing, to primary care, and to drug treatment and mental health services, but not to syringe exchange. For example, the odds of providers more frequently linking clients to HIV testing are two and four times greater for those providers who were exposed to three EBIs and to four or more EBIs, respectively. The odds of providers more frequently linking clients to primary care are about 1.5 and 2 times greater for those providers who were exposed to three and four or more EBIs, respectively. Compared with supervisors, navigators linked clients more frequently to primary care but less frequently to drug treatment. Compared with supervisors, educators linked clients less frequently to primary care, drug treatment, and mental health services. Providers with caseloads more than 50 clients per week made more frequent linkages to primary care, drug treatment, and mental health services, compared with providers with caseloads of 30 or fewer. Providers in agencies with in-house HEP-C testing made the most linkages for HEP-C testing.

\section{Discussion}

In 1994, before DEBI and HIP, local and state health departments began to deliver HIV prevention services - counseling, testing, and referral to support services (CDC, 2006). Our findings lend support to the concept of "exposure" to build knowledge about how a system-level project (i.e., DEBI) can influence adoption of services (i.e., linkage-making) under a subsequent project (i.e., HIP). To our knowledge, the concept of "exposure" has not been used in research concerning the HIV Continuum of Care, and it is thus an innovation.

Findings show that providers exposed to EBIs make significantly more linkages to high-impact interventions; the average rate of linkages is basically the same whether or not the agency offers a particular service ("in-house"). Some providers refer their clients to outside services even when their agencies have those services, for example, to preserve their clients' anonymity. The results suggest a dose effect, with exposure to more EBIs resulting in more frequent linkages. Providers exposed to one EBI may become knowledgeable about that EBI, develop positive attitudes about that EBI, become confident about their abilities to deliver that EBI, and thus adopt other types of EBIs. Providers seldom link clients to syringe exchange, perhaps because some agencies do not serve large numbers of persons who inject drugs, some providers may adhere to an abstinence-only paradigm, or clients 


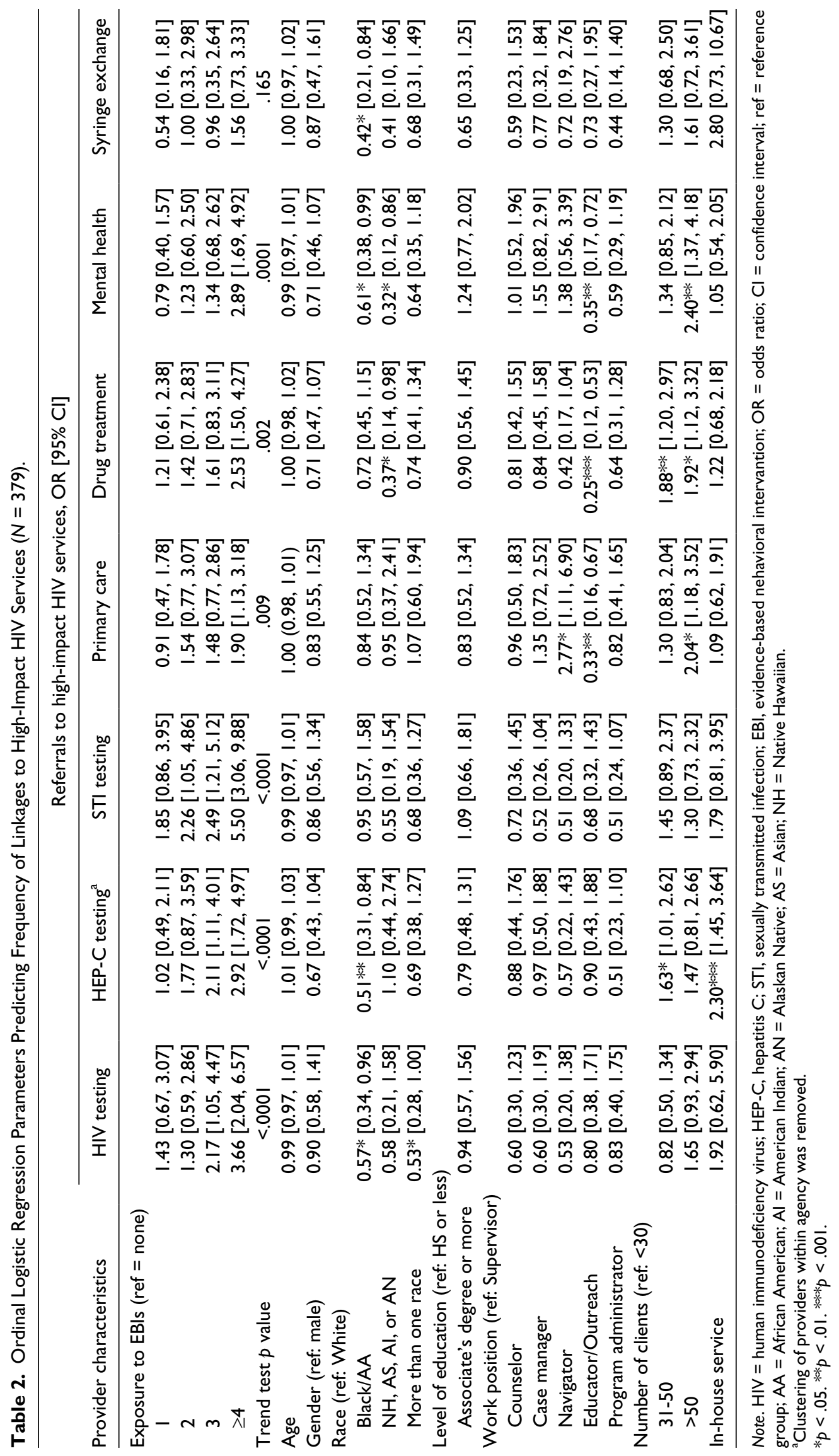


do not feel comfortable revealing drug use to providers. Frequency of linkages to HEP-C testing was low. HEP-C testing takes place within primary care, so providers may assume that linkages to primary care will include HEP-C testing.

Client navigators guide clients through the health care system to increase retention in care by using intensive contact in the first 6 months of care. Health educators offer educational workshops and programing specific to HIV prevention and strive to engage at-risk populations. Navigators and educators linked clients to drug treatment and mental health services less frequently than supervisors. Supervisors often link clients to services with "special considerations," like cost, waiting lists, and age or gender. Larger caseloads, regardless of work position, predicted more linkages to primary care, drug treatment and mental health. In HIP, all providers are encouraged to participate by linking clients to all high-impact services. Our findings show that navigators more frequently link clients to primary care. This calls for research to uncover the specific techniques they use and which might be used by other providers to improve linkages.

Non-White providers were less likely to link clients to certain services, perhaps due to racial disparities in levels of trust in how high-impact services were launched without strong participation of the community. The data do not allow us to test an explanation, but we recommend research to explore the role of race in delivering HIP services. This is especially important given that a disproportionate number of individuals of color are living with or becoming infected with HIV and in need of HIP services.

\section{Limitations}

Limitations include a convenience sample that does not represent the universe of agencies in NYC. We used a crosssectional design and cannot report on causal associations. Access to syringe exchanges does not necessitate linkages, per se; therefore, the question we used to assess linkages should have asked whether or not providers shared information about exchange programs. We note the importance of assessing the degree of linkage-making before DEBI and HIP; however, we do not have data before HIP. Being unable to confirm the "success" of linkages is also a limitation; nonetheless, we know from experience that $90 \%$ to $100 \%$ of linkages are completed successfully. The data we used are the best available; future research should focus on agencies with similar documentation systems to compare successful versus unsuccessful linkages. Longitudinal studies are needed to examine the context in which linkages are made and the factors that hinder linkage completion.

\section{Implications for Policy and Practice}

We identified a staged approach to HIV prevention. Providers were first exposed to DEBI requiring them to offer multiple EBIs. Then, under HIP, they were required to offer all high-impact services. This shift begs some questions about practice (Johns, Bayer, \& Fairchild, 2016; Purcell, McCray, $\&$ Mermin, 2016). All EBIs have positive effects for at least one HIV risk behavior; however, positive effects are not maintained over long periods of time (Feldman, Silapaswan, Schaefer, \& Schermele, 2014). With unwanted consequences, the CDC has supported only cost-effective EBIs for populations with the greatest HIV burden (CDC, 2015b). For example, de-adoption of RESPECT, an individual-level EBI to reduce HIV risks, has created a disconnect among agency services and frustration among staff (McKay, Dolcini, \& Hoffer, 2017). Research on de-adoption is needed to examine further effects of de-emphasis of long-running practices and of providers' trust in public health science. There may be no prevention community with a longer history of engaged advocacy, yet it is unclear to what extent decision-making around de-adoption involved providers.

As policies change the focus of practice, agencies adapt to new mandates. Future policies concerning HIV prevention ought to consider the benefit of exposing providers to one type of service as a strategy to potentiate adoption of subsequent other services. Agency- and provider-level diversity in our sample makes us confident that results will have similar implications for urban diffusion systems across the United States. Since at-risk individuals are not consistently linked to or retained in care, there needs to be a continued emphasis on inspiring providers to engage with high-impact services at the elevated levels needed to end the epidemic.

\section{Acknowledgments}

We would like to thank Charles B Collins, Jr., PhD, Capacity Building Branch Division of HIV/AIDS Prevention National Center for HIV, STD and TB Prevention for his indispensable comments on the historical and contextual aspects of this article. We also wish to thank the members of the Implementation Community Collaborative Board for their varied contributions to this article: Karen L. Baird, Rosa Bramble, Jeannette Ruffins, Charles Sanky, and Wendy Whitman.

\section{Declaration of Conflicting Interests}

The authors declared no potential conflicts of interest with respect to the research, authorship, and/or publication of this article.

\section{Funding}

The authors disclosed receipt of the following financial support for the research, authorship, and/or publication of this article: This study was funded by The United States National Institute of Mental Health (R01MH095676).

\section{References}

Baeten, J. M., Strick, L. B., Lucchetti, A., Whittington, W. L., Sanchez, J., Coombs, R. W., . . . Celum, C. (2008). Herpes simplex virus (HSV)-suppressive therapy decreases plasma and genital HIV-1 levels in HSV-2/HIV-1 coinfected women: 
A randomized, placebo-controlled, cross-over trial. Journal of Infectious Diseases, 198, 1804-1808. doi:10.1086/593214

Carey, J. W., LaLota, M., Villamizar, K., McElroy, T., Wilson, M. M., Garcia, J., . . . Flores, S. A. (2015). Using high-impact HIV prevention to achieve the National HIV/AIDS strategic goals in Miami-Dade County, Florida: A case study. Journal of Public Health Management \& Practice, 21, 584-593.

Center for Training and Research Translation. (2012). Center Training and Research Translation Evaluation Framework. Retrieved from http://www.centertrt.org/?p=evaluation_framework

Centers for Disease Control and Prevention. (2006). Evolution of HIV/AIDS Prevention programs: United States, 1981-2006 (21). Retrieved from http://www.cdc.gov/mmwr/preview/ mmwrhtml/mm5521a4.htm

Centers for Disease Control and Prevention. (2015a). Compendium of Evidence-Based Interventions and Best Practices for HIV Prevention NEW Linkage to, Retention in, and Re-engagement in HIV Care (LRC) Chapter. Retrieved from http://www.cdc. gov/hiv/prevention/research/compendium/lrc/index.html

Centers for Disease Control and Prevention. (2015b). High Impact HIV Prevention (HIP): Overview of select interventions \& strategies. Washington, DC: Danya International. Retrieved from https://effectiveinterventions.cdc.gov/docs/default-source/general-docs/15-1106-hip-overview-factsheet.pdf?sfvrsn=2

Centers for Disease Control and Prevention. (2016). HIV survelliance report. Retrieved from https://www.cdc.gov/hiv/pdf/library/ reports/surveillance/cdc-hiv-surveillance-report-2015-vol-27.pdf

Centers for Disease Control and Prevention, National Center for HIV/AIDS, Viral Hepatitis, STD, and TB Prevention Division of HIV/AIDS Prevention. (2011). High-impact HIV prevention: CDC's approach to reducing HIV infections in the United States. Atlanta, GA: Author. Retrieved from http://www.cdc. gov/hiv/pdf/policies_NHPC_Booklet.pdf

Cohen, M. S., Chen, Y. Q., McCauley, M., Gamble, T., Hosseinipour, M. C., Kumarasamy, N., ... Team, H. S. (2011). Prevention of HIV-1 infection with early antiretroviral therapy. New England Journal of Medicine, 365, 493-505. doi:10.1056/ NEJMoa1105243

Cohen, M. S., McCauley, M., \& Gamble, T. R. (2012). HIV treatment as prevention and HPTN 052. Current Opinion in HIV and AIDS, 7(2), 99-105.

Del Rio, C., \& Mayer, K. (2013). Editorial commentary: A tale of 2 realities: What are the challenges and solutions to improving engagement in HIV care? Clinical Infectious Diseases, 57, 1172-1174. doi:10.1093/cid/cit426

Dodd, P. J., Garnett, G. P., \& Hallett, T. B. (2010). Examining the promise of HIV elimination by "test and treat" in hyperendemic settings. AIDS, 24, 729-735. doi:10.1097/ QAD.0b013e32833433fe

Feldman, M. B., Silapaswan, A., Schaefer, N., \& Schermele, D. (2014). Is there life after DEBI? Examining health behavior maintenance in the diffusion of effective behavioral interventions initiative. American Journal of Community Psychology, 53, 286-313. doi:10.1007/s10464-014-9629-3

Fleming, D. T., \& Wasserheit, J. N. (1999). From epidemiological synergy to public health policy and practice: The contribution of other sexually transmitted diseases to sexual transmission of HIV infection. Sexually Transmitted Infections, 75, 3-17. doi:10.1136/sti.75.1.3
Fuller, C. M., Ford, C., \& Rudolph, A. (2009). Injection drug use and HIV: Past and future considerations for HIV prevention and interventions. London, England: Academic Press/Elsevier.

Gardner, L. I., Marks, G., Craw, J. A., Wilson, T. E., Drainoni, M. L., Moore, R. D., . . Retention in Care Study Group. (2012). A low-effort, clinic-wide intervention improves attendance for HIV primary care. Clinical Infectious Diseases, 55, 11241134. doi: $10.1093 / \mathrm{cid} / \mathrm{cis} 623$

Johns, D. M., Bayer, R., \& Fairchild, A. L. (2016). Evidence and the politics of deimplementation: The rise and decline of the "counseling and testing" paradigm for HIV prevention at the US Centers for Disease Control and Prevention. Milbank $Q$, 94, 126-162.

Kaaya, S., Eustache, E., Lapidos-Salaiz, I., Musisi, S., Psaros, C., \& Wissow, L. (2013). Grand challenges: Improving HIV treatment outcomes by integrating interventions for co-morbid mental illness. PLos Medicine, 10(5), e1001447. doi:10.1371/ journal.pmed.1001447

Dolcini, M., Gandelman, A. A., Vogan, S. A., Kong, C., Leak, T. N., King, A. J., . . . O'Leary, A. (2010). Translating HIV interventions into practice: Community-based organizations' experiences with the diffusion of effective behavioral interventions (DEBIs). Social Science \& Medicine, 71, 1839-1846. doi:10.1016/j.socscimed.2010.08.011

McKay, V. R., Dolcini, M., \& Hoffer, L. D. (2017). The dynamics of de-adoption: a case study of policy change, de-adoption, and replacement of an evidence-based HIV intervention. Translational Behavioral Medicine, 7, 821-831. doi:10.1007/ s13142-017-0493-1

Mugavero, M. J., Norton, W. E., \& Saag, M. S. (2011). Health care system and policy factors influencing engagement in HIV medical care: Piecing together the fragments of a fractured health care delivery system. Clinical Infectious Diseases, 52(Suppl. 5), S238-S246. doi:10.1093/cid/ciq048

National Center for HIV/AIDS, Viral Hepatitis, STD, and TB Prevention Division of HIV/AIDS Prevention. (2015). CDC awards $\$ 216$ million to community-based organizations to deliver the most effective HIV prevention strategies to those in greatest need [Press release]. Retrieved from https://www.cdc. gov/nchhstp/newsroom/2015/cbo-foa-awards-press-release.html

Panel on Antiretroviral Guidelines for Adults and Adolescents. (2016). Guidelines for the use of antiretroviral agents in HIV1-infected adults and adolescents. Retrieved from http://www. aidsinfo.nih.gov/ContentFiles/AdultandAdolescentGL.pdf

Pinto, R. M., Spector, A., Rahman, R., \& Gastolomendo, J. D. (2015). Research advisory board members' contributions and expectations in the USA. Health Promotion International, 30, 328-338. doi:10.1093/heapro/dat042

Pinto, R. M., Spector, A. Y., \& Valera, P. A. (2011). Exploring group dynamics for integrating scientific and experiential knowledge in Community Advisory Boards for HIV research. AIDS Care, 23, 1006-1013.

Pinto, R. M., Witte, S., Filippone, P., Whitman, W., \& Baird, K. (2017). Factors that influence linkages to HIV continuum of care services: Implications for multi-level interventions. International Journal of Environmental Research and Public Health. Advance online publication. doi:10.3390/ijerph14111355

Porco, T. C., Martin, J. N., Page-Shafer, K. A., Cheng, A., Charlebois, E., Grant, R. M., \& Osmond, D. H. (2004). Decline in HIV infectivity following the introduction of highly active 
antiretroviral therapy. AIDS, 18, 81-88. doi:10.1097/01. aids.0000096872.36052.24

Purcell, D. W., McCray, E., \& Mermin, J. (2016). The shift to highimpact HIV prevention by health department in the United States. Public Health Reports, 131, 7-10.

Rapp, R. C., Ciomcia, R., Zaller, N., Draine, J., Ferguson, A., \& Cagey, R. (2013). The role of jails in engaging PLWHA in care: From jail to community. Aboriginal and Islander Health Work Journal, 17(Suppl. 2), S89-S99. doi:10.1007/s10461-012-0298-7

Rogers, E. M. (1995). Diffusion of innovations (4th ed.). New York, NY: Simon \& Schuster.

Thompson, M. A., Mugavero, M. J., Amico, K. R., Cargill, V. A., Chang, L. W., Gross, R., . . Nachega, J. B. (2012). Guidelines for improving entry into and retention in care and antiretroviral adherence for persons with HIV: Evidencebased recommendations from an international association of physicians in AIDS Care Panel. Annals of Internal Medicine, 256, 817-833.

UNAIDS. (2014). 90-90-90 An ambitious treatment target to help end the AIDS epidemic. Geneva, Switzerland: Author. Retrieved from http://www.unaids.org/sites/default/files/media_asset/9090-90_en_0.pdf

Zaller, N., Fu, J. J., Nunn, A., \& Beckwith, C. G. (2011). Linkage to care for HIV-infected heterosexual men in the United States. Clinical Infectious Diseases, 52(Suppl. 2), S223-S230. doi:10.1093/cid/ciq046

Zuckerman, R. A., Lucchetti, A., Whittington, W. L., Sanchez, J., Coombs, R. W., Zuñiga, R., . . Celum, C. (2007). Herpes simplex virus (HSV) suppression with valacyclovir reduces rectal and blood plasma HIV-1 levels in HIV-1/HSV-2-seropositive men: A randomized, double-blind, placebo-controlled crossover trial. Journal of Infectious Diseases, 196, 1500-1508. 